\title{
Os benefícios fiscais para os agrotóxicos: um debate acerca de sua (in) constitucionalidade a partir do Estado de Direito Ambiental e da ordem pública ambiental
}

Tax incentives for pesticides: a debate on its (un) constitutionality from the environmental rule of law and the environmental public order

\author{
João Alfredo Telles Melo* \\ Geovana de Oliveira Patrício Marques**
}

\begin{abstract}
RESUMO: O objetivo deste trabalho é analisar a (in)constitucionalidade dos benefícios tributários concedidos aos agrotóxicos, tendo como base o conceito de "Estado de Direito Ambiental". Para tanto, uma análise inicial da crise ambiental planetária é apresentada, a fim de introduzir a questão dos danos socioambientais causados por estes agroquímicos. Por meio do estudo de princípios fundamentais essenciais à dignidade humana, tais como o Direito ao Meio Ambiente Ecologicamente Equilibrado, da solidariedade (ou equidade) intergeracional, da precaução e da atuação preventiva, assim como da análise do conceito de extrafiscalidade, pode-se avaliar os benefícios tributários concedidos - ICMS, PIS/PASEP, COFINS e IPI - aos produtos agrotóxicos. Esta pesquisa foi construída mediante amplo estudo teórico e bibliográfico. Apresentar-se-á a inconstitucionalidade desses benefícios, o que configura um fenômeno que se pode denominar de "extrafiscalidade às avessas".
\end{abstract}

PALAVRAS-CHAVE: Meio ambiente; Agrotóxicos; Benefícios tributários; Princípios fundamentais; Inconstitucionalidades.

ABSTRACT: The objective of this work is to analyze the (un)constitutionality of the tax benefits granted to pesticides, based on the concept of "State of Environmental Law." To this end, an initial analysis of the global environmental crisis is presented to introduce the issue of environmental damage caused by these agrochemicals. Through the study of fundamental rights essential to human dignity, such as the right to an ecologically balanced environment, intergenerational solidarity (or equity), the precautionary and preventive actions, as well as through the analysis of the concept of extrafiscality, we evaluate the tax benefits granted ICMS, PIS / PASEP, COFINS and IPI - to pesticide products. This research was built upon vast theoretical and bibliographical study. It concludes that those benefits are unconstitutional, what currently is a phenomenon that could be treated as an "extrafiscality backwards".

KEYWORDS: Environment; Pesticides; Tax benefits; Fundamental principles; Unconstitutional.

\footnotetext{
* Advogado, professor de Direito Ambiental da FA7, mestre em Direito Público (UFC), doutorando no Programa de Desenvolvimento e Meio Ambiente (UFC) e vereador em Fortaleza. E-mail: joaoalfredotellesmelo@gmail.com.

** Bacharel em Direito pela Faculdade Sete de Setembro (FA7). Advogada. E-mail: geovanapm@hotmail.com. Data de recebimento do artigo: 01/02/2016 - Data de avaliação: 15/02/2016 e 15/02/2016.
} 
Os benefícios fiscais para os agrotóxicos: um debate acerca de sua (in) constitucionalidade a partir do Estado de Direito Ambiental e da ordem pública ambiental

\section{INTRODUÇÃO}

"Ser capaz, como um rio / que leva sozinho/a canoa que se cansa, / de servir de caminho /para a esperança." (Thiago de Mello).

$\mathrm{O}$ artigo pretende discutir a (in)constitucionalidade de dispositivos normativos que concedem uma série de benefícios tributários voltados para a produção, importação e comercialização de agrotóxicos em nosso país. Partimos da compreensão de que se o Brasil é o maior consumidor mundial desses agroquímicos, isso se dá por conta de uma série de incentivos fiscais, financeiros e técnicos voltados para a utilização desses insumos na agricultura.

Os dados da referida indústria do veneno são estarrecedores: desde 2008, o Brasil consome cerca de 1 milhão de toneladas de produtos agrotóxicos por ano, o que representa um consumo em torno de 5 litros por habitante/ano (LONDRES, 2011, p. 19). No Brasil, no ano de 2007, estavam registrados cerca de 1.400 agrotóxicos, 430 ingredientes ativos e 750 produtos técnicos (CARNEIRO, 2015, p. 53). Um negócio que, em 2012, movimentou 9,710 bilhões de dólares (VALOR ECONÔMICO, 2013) e que tem, conforme veremos a seguir, trazido graves impactos e danos à saúde humana e à higidez ambiental em nosso país, que ostenta o triste primeiro lugar nesse tétrico campeonato de consumo de venenos.

Iniciamos nossas reflexões com a contextualização da ampla utilização desses agroquímicos em um cenário de crise socioambiental de natureza planetária, onde a poluição, em seus diversos aspectos, é um sinal - mas não o único - dessa "esquina" civilizatória em que a humanidade se encontra na presente quadra.

Debruçando-se sobre a crise, Morin e Kern (2005), ao analisar a "agonia planetária", conceituam o estado da arte da "Terra-Pátria" e da "Humanidade-comunidade de destino" como "policrise", ou "conjunto policrístico", num entrelaçamento das crises do desenvolvimento, da modernidade e das sociedades; uma crise civilizatória, portanto. Da civilização do capital, do sistema produtor de mercadoria, acrescentar-se-ia.

Em seguida, o trabalho se voltará para um debate acerca da Constituição de 1988 - que, na expressão de Marlmestein, criou “[...] as bases para o florescimento de uma nova ordem democrática" (2013, p. 15), sua consequente e expressiva carga valorativa, o que vem a configurar uma verdadeira “ordem pública ambiental”, instituída pela fórmula política do “Estado de Direito Ambiental”, na concepção de Benjamin (2008) e de outros doutrinadores. 
João Alfredo Telles Melo e Geovana de Oliveira Patrício Marques

Aqui serão apresentados alguns princípios do Direito Ambiental, que vão servir de parâmetro para o debate da última parte deste paper. Portanto, o recorte acerca da constitucionalidade dessas normas se dará a partir dos parâmetros expostos acima.

Finalmente, no terceiro momento, far-se-á uma breve apresentação das normas que concedem os benefícios fiscais para os agrotóxicos e o que fundamenta essa política. Nas conclusões, ao se articular o aspecto fático da poluição e contaminação causadas pelos agroquímicos com o aspecto valorativo dos princípios emanados pela Carta de 1988, traremos o tema de sua (in)constitucionalidade.

\section{O FATO: A CONTAMINAÇÃO DOS AGROTÓXICOS NO CONTEXTO DE UMA CRISE SOCIOAMBIENTAL DE NATUREZA PLANETÁRIA}

\footnotetext{
"O mundo natural fora das nossas fazendas e cidades não existe como decoração, mas serve para regular a química e o clima da Terra, e os ecossistemas são os órgãos de Gaia que lhe permitem manter nosso planeta habitável" (James Lovelock).
}

Hoje, pode se dizer que há quase um consenso de que o planeta está imerso em uma crise socioambiental de natureza planetária e de proporções ainda não vividas pela sociedade humana. Sua face mais grave e mais visível, mas não única, são o superaquecimento da Terra e as mudanças climáticas. Ainda que já tenha sido apresentado, em 2015, o $5^{\circ}$ Relatório de Avaliação de Mudanças Climáticas do Painel Intergovernamental de Mudanças Climáticas (IPCC, em sua sigla em inglês), foi a divulgação, em fevereiro de 2007, do relatório anterior que causou um grande impacto, dadas as suas gravíssimas conclusões. Tal documento traz conclusões sobre as mudanças no clima e seus efeitos na vida na Terra. Afirma, ainda, que o aquecimento do sistema climático é inequívoco; que suas causas, ligadas à emissão de gases do efeito estufa (GEEs), são antropogênicas e não naturais; e que seus impactos sobre a natureza e a sociedade já se fazem sentir (IPCC, 2015).

Não há um dia em que não se observe a ocorrência, em qualquer parte do mundo, de algum fenômeno climático-ambiental extremo: secas, tufões, enchentes, etc., fenômenos que têm sido cada vez mais intensos e recorrentes, a ponto de um termo do vocabulário de guerra ter sido adaptado para o repertório ecológico: o "refugiado climático", ou "refugiado ambiental", que já se conta em milhões no planeta. A Cruz Vermelha Internacional, que publicou, em 2001, o Relatório Mundial de Desastres, projeta a existência de 200 milhões de 
Os benefícios fiscais para os agrotóxicos: um debate acerca de sua (in) constitucionalidade a partir do Estado de Direito Ambiental e da ordem pública ambiental

refugiados climáticos em 2050 (HOOD, 2007).

No entanto, como já aludido, o aquecimento global e as mudanças climáticas são apenas a face mais visível de uma crise maior, que se relaciona à atual configuração do modo de produção capitalista, com seu modelo de desenvolvimento fundado na matriz fóssil e em uma visão produtivista, que sustenta um modo de vida das elites econômicas mundiais baseado no consumo perdulário, que é, a um só tempo, ambientalmente insustentável e socialmente injusto, não só em escala regional ou nacional, mas também no âmbito planetário.

Foster, autor do clássico “A Ecologia de Marx: materialismo e natureza” (2005), em um instigante artigo de 2008, intitulado "Organizar a Revolução Ecológica", lista os sinais de advertência da crise ambiental global, demonstrando a insustentabilidade do percurso da humanidade nestes tempos atuais, dentre os quais se destaca um dado extremamente significativo e grave da crise, que é muito pouco divulgado: a ruptura da capacidade regenerativa do planeta, do seu equilíbrio. Em suas palavras:

\footnotetext{
De acordo com um estudo publicado em 2002 pela National Academy of Sciences, a economia mundial excedeu a capacidade regenerativa da terra em 1980 e em 1999 ultrapassou-a em 20 por cento. Isto significa, segundo os autores do estudo, que 'seriam precisas 1,2 terras, ou uma terra por cada 1,2 anos, para regenerar o que a humanidade utilizou em 1999’ (2015).
}

$\mathrm{Na}$ verdade, o que ocorre é que, como adverte um manifesto que foi assinado por 29 cientistas mundiais e publicado na revista Nature de 24 de setembro de 2009 - conforme noticia Tuma na revista Carta Capital do dia seguinte, em sugestivo artigo intitulado "Antropoceno, a era da destruição" —, "[...] as atividades diárias dos 6 bilhões de humanos resultam, por si, em uma força geofísica capaz de mudar completamente a Terra, equivalente às grandes forças da natureza" (2015).

A poluição do ar encontra-se entre as consequências dessas atividades. A Organização Mundial da Saúde (2015) divulgou que, só no ano de 2012, 7 milhões de pessoas morreram por exposição à poluição do ar, que se tornou o maior fator de risco ambiental no mundo. Doenças cardiovasculares, pulmonares e câncer se encontram como causa mortis dessa tétrica estatística.

Com certeza, uma parte - ainda que não se possa dimensioná-la - dessa poluição criminosa é causada pela aspersão (via pulverização aérea, por tratores ou manualmente) de agrotóxicos (abra-se aqui parênteses para dizer que há outras formas de contaminação pelos venenos agrícolas). A dificuldade de se ter essa mensuração é a sua subnotificação. Relatam 
Augusto et al. (2011, p. 259) que "[...] para cada caso registrado de intoxicação por agrotóxico ocorrem outros 50 sem notificação, ou com notificação errônea. Afirmam, ainda, que $70 \%$ das intoxicações ocorrem em países pobres ou em desenvolvimento (2011, p. 259), o que se configura claramente como mais um caso de injustiça ambiental ${ }^{l}$.

Ainda assim, os dados de contaminação são bastante significativos em nosso país. Rosa, Pessoa e Rigotto, em estudo sobre os impactos dos agroquímicos sobre a saúde humana, afirmam, de acordo com os dados do Sistema Nacional de Informações TóxicoFarmacológicas (Sinitox), entre 1989 e 2004, que foram notificados mais de 1 milhão de casos de intoxicações humanas pelos venenos químicos. Das pessoas intoxicadas, 6.632 vieram a óbito (2011, p. 240).

Dentre esses óbitos, um chama atenção, o de Vanderlei Matos da Silva, operário da Del Monte Fresh Produce Brasil Ltda, em Limoeiro do Norte, Ceará, em 30 de novembro de 2008, pelo fato de a justiça trabalhista em primeiro e em segundo grau ter reconhecido que sua morte se deu por hepatopatia crônica, resultante do contato com substâncias tóxicas (SILVA, 2015; DIÁRIO DO NORDESTE, 2014).

Por sua vez, Nodari dá notícia de “[...] centenas de estudos de pesquisadores independentes que relatam os possíveis efeitos toxicológicos crônicos ou agudos de muitos produtos", e exemplifica os efeitos: "[...] reprodutivos, teratogênicos, mutagênicos, carcinogênicos e nervosos, entre outros". Adverte, ainda, para o fato de que tais efeitos podem decorrer tanto da atividade ocupacional, como da ingestão de resíduos de agrotóxicos (2012, p. 119).

Ao longo dos anos, vem-se constatando que esses produtos químicos eliminam insetos necessários ao equilíbrio das plantas, contaminam a terra, o ar e o lençol freático. Assim, poluem e causam danos incalculáveis ao meio ambiente. $\mathrm{Na}$ sua aplicação, acabam se dispersando no ar e, consequentemente, são carregados pelas chuvas para os rios, contaminando o solo e o lençol freático. Não há como não relacionar o aumento da utilização dos agrotóxicos - e da contaminação por eles causada - com a expansão do agronegócio no país, cujo modelo leva a outros grandes impactos socioambientais, como o desmatamento, o monocultivo em grandes extensões, a alteração da microfauna do solo, etc.

São enormes os danos causados à saúde humana devido ao manuseio nas atividades

\footnotetext{
${ }^{1}$ Injustiça ambiental: "mecanismo pelo qual sociedades desiguais, do ponto de vista econômico e social, destinam a maior carga dos danos ambientais do desenvolvimento às populações de baixa renda, aos grupos raciais discriminados, aos povos étnicos tradicionais, aos bairros operários, às populações marginalizadas e vulneráveis" (cf. ACSERLRAD, Henri et al; 2009).
} 
Os benefícios fiscais para os agrotóxicos: um debate acerca de sua (in) constitucionalidade a partir do Estado de Direito Ambiental e da ordem pública ambiental

laborais, à contaminação ambiental, inclusive da água, e à ingestão de produtos contaminados. Conforme Braga, “[...] os defensivos presentes no solo transferem-se, parcialmente, para o tecido celular da planta, com relações de concentrações que dependem, entre outros fatores, da concentração existente no solo e do tipo de planta" (2014, p. 143).

A ingestão, por parte da população, de alimentos contaminados com resíduos dos venenos químicos é gravíssima em nosso país, como se pode ver no gráfico abaixo. A avaliação de alguns alimentos pelo Programa de Análise de Resíduos Agrotóxicos em Alimentos (PARA) da Anvisa demonstrou um alto e insatisfatório nível de contaminação:

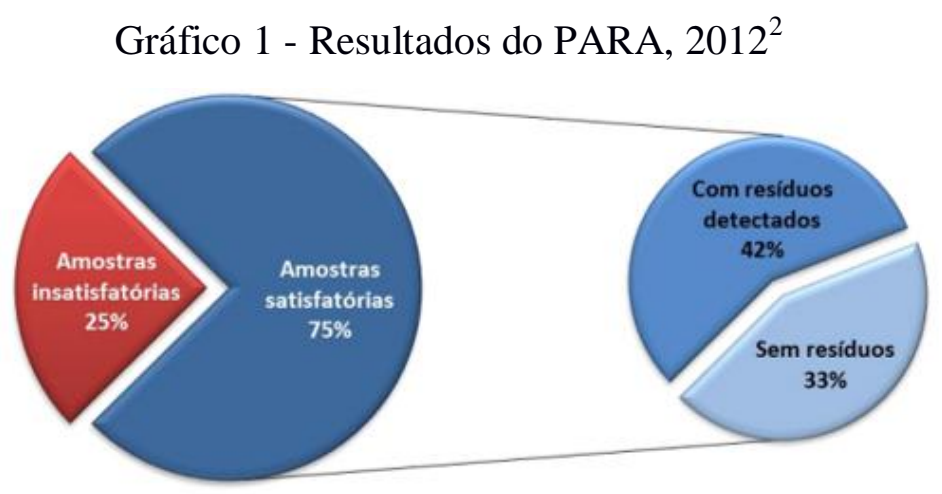

Fonte: Agência Nacional de Vigilância Sanitária

Tabela 1 - Resultados do PARA 2012

\begin{tabular}{|c|c|c|c|c|c|c|c|c|c|}
\hline \multirow{3}{*}{ Produto } & \multirow{3}{*}{$\begin{array}{c}\mathrm{N}^{\circ} \text { de } \\
\text { amostras } \\
\text { Analisadas }\end{array}$} & \multicolumn{2}{|c|}{ NA } & \multicolumn{2}{|c|}{$>$ LMR } & \multicolumn{2}{|c|}{$>$ LMR e NA } & \multicolumn{2}{|c|}{$\begin{array}{c}\text { Total de } \\
\text { Insatisfatórios }\end{array}$} \\
\hline & & \multicolumn{2}{|c|}{ (1) } & \multicolumn{2}{|c|}{ (2) } & \multicolumn{2}{|c|}{ (3) } & \multicolumn{2}{|c|}{$(1+2+3)$} \\
\hline & & $\mathrm{N}^{0}$ & $\%$ & $\mathbf{N}^{\circ}$ & $\%$ & $\mathrm{~N}^{0}$ & $\%$ & $\mathrm{~N}^{0}$ & $\%$ \\
\hline Abobrinha & 229 & 104 & $45 \%$ & 5 & $2,2 \%$ & 1 & $0,4 \%$ & 110 & $48 \%$ \\
\hline Alface & 240 & 93 & $39 \%$ & 2 & $0,8 \%$ & 12 & $5,0 \%$ & 107 & $45 \%$ \\
\hline Feijão & 245 & 10 & $4,1 \%$ & 4 & $1,6 \%$ & 4 & $1,6 \%$ & 18 & $7,3 \%$ \\
\hline Fubá de Milho & 208 & 2 & $1,0 \%$ & 4 & $1,9 \%$ & 0 & $0,0 \%$ & 6 & $2,9 \%$ \\
\hline Tomate & 246 & 28 & $11,4 \%$ & 6 & $2,4 \%$ & 5 & $2,0 \%$ & 39 & $16 \%$ \\
\hline Uva & 229 & 57 & $25 \%$ & 5 & $2,2 \%$ & 5 & $2,2 \%$ & 67 & $29 \%$ \\
\hline TOTAL & 1397 & 294 & $21 \%$ & 26 & $1,9 \%$ & 27 & $1,9 \%$ & 347 & $25 \%$ \\
\hline
\end{tabular}

(1) amostras que apresentaram somente ingredientes ativos não autorizados (NA); (2) amostras somente com ingredientes ativos autorizados, mas acima dos limites máximos autorizados (> LMR); (3) amostras contendo as duas irregularidades (NA e > LMR); $(1+2+3)$ soma de todos os tipos de irregularidades.

A avaliação realizada nesses alimentos se baseia em um nível de segurança para o consumo humano. No entanto, nesses testes, não são analisados todos ingredientes ativos, o 
que não permite afirmar a ausência de outros ${ }^{3}$.

Os custos para o tratamento das doenças e óbitos ocasionados pelo uso dos agrotóxicos são internalizados pela sociedade, como bem coloca Codonho, enquanto às empresas que os utilizam em sua cadeia de produção cabe apenas auferir os lucros gerados por esta prática. Ainda segundo a pesquisadora, "[...] foi realizado um estudo no Estado do Paraná, no qual se estimou que, para cada dólar gasto com a compra dos agrotóxicos no Estado, cerca de US\$ 1,28 poderiam ser gerados em custos externos por intoxicação" (2014, p. 40-41).

Por sua gravidade, este trabalho seria pequeno para listar a quantidade e qualidade dos impactos causados pelos agrotóxicos ao meio ambiente, à vida e à saúde. A literatura é vasta; as notícias são muitas ${ }^{4}$. O fato é que já se pode afirmar, com vários pesquisadores, que não é possível o uso seguro de agrotóxicos em nosso país, por uma série de fatores que Rosa, Pessoa e Rigotto, em artigo já citado, elencam: a magnitude do uso de agrotóxicos no país; a extensão do universo que teria que ser fiscalizado e controlado; a falta de condições institucionais e estruturais dos órgãos de comando e controle; a insuficiente formação e capacitação dos agricultores; etc. À mesma conclusão chegou o pesquisador Pedro Henrique de Abreu (apud SALLES, 2015), do Programa de Pós-Graduação de Saúde Coletiva da Universidade Estadual de Campinas (Unicamp). O fato de que a população brasileira consome 22 tipos de agrotóxicos que são proibidos na União Europeia só reforça essa insegurança (CARNEIRO, 2015, p. 53).

Ora, se não é seguro o uso dos agrotóxicos; se estes têm causado danos tão graves à higidez ambiental e à sanidade humana, como se justifica que esses insumos tenham incentivos para as suas produção, importação e comercialização? Seriam constitucionais as normas que lhes dão benefícios fiscais? Antes de responder a essas questões, se faz importante analisar o conteúdo valorativo de nossa Constituição, especialmente em seu aspecto ambiental.

\footnotetext{
${ }^{3} \mathrm{O}$ paraquat e o glifosato não foram analisados, sendo que estes herbicidas são utilizados em grande escala no Brasil.

${ }^{4} \mathrm{O}$ caso do envenenamento das abelhas é, certamente, um dos mais trágicos, ainda que não seja o único. Disponível em: <http://outraspalavras.net/posts/o-envenenamento-das-abelhas/>. Acesso em 29 mar. 2015.
} 
Os benefícios fiscais para os agrotóxicos: um debate acerca de sua (in) constitucionalidade a partir do Estado de Direito Ambiental e da ordem pública ambiental

\section{O VAlOR: UMA CONSTITUIÇÃO EMBEBIDA DE PRINCÍPIOS, A ORDEM PÚBLICA AMBIENTAL E O ESTADO DE DIREITO AMBIENTAL}

\footnotetext{
"A ecologização do texto constitucional traz um certo sabor herético, deslocado das fórmulas antecedentes, ao propor a receita solidarista - temporal e materialmente ampliada (e, por isso mesmo, prisioneira de traços utópicos) - do nós-todos-em-favor-do-planeta." (Antonio Herman Benjamin)
}

O Direito Ambiental - entendido como sistematização de normas, princípios, doutrina e jurisprudência que busca disciplinar a relação da sociedade humana com o seu entorno natural - é, em última análise, filho da atual crise socioambiental acima referida, que coloca em risco não só a sobrevivência de nossa espécie, mas da vida como um todo, em nossa pequena nave planetária. Tanto que o surgimento desse novo ramo jurídico, em escala internacional, pode ser encontrado nos documentos produzidos durante a I Conferência sobre o Meio Ambiente Humano, realizada em Estocolmo, no ano de 1972, convocada para debater os problemas ambientais, que já alcançavam uma dimensão global (MILARÉ, 2014, p. 251).

O impacto dessa crise no âmbito do Direito se dá no fenômeno recíproco que Benjamin (2008) denomina de "Constitucionalização do Ambiente e Ecologização do Direito", o que leva a doutrina a encontrar em nossa Carta Magna (e em outras que se assemelham pela mesma fórmula política) elementos do que poderia se chamar, com Canotilho (2008), de "Estado de Direito Democrático e Ambiental", ou, em Sarlet e Fensterseifer (2010), de "Estado Socioambiental de Direito", ou, ainda, em Leite, de "Estado de Direito Ambiental”, para quem essa forma de organização deve buscar “[...] uma condição ambiental capaz de favorecer a harmonia entre os ecossistemas e, consequentemente, garantir a plena satisfação da dignidade para além do ser humano" (2011, p. 53).

A concepção de que a fórmula política de nossa Constituição de 1988 é um Estado de Direito Ambiental (ou, numa definição mais detalhista, Estado Democrático Socioambiental de Direito), decorre da síntese dialética "pós-positivista”, que supera, nas palavras de Belchior (2011, p. 90), com um novo conceito, a antinomia jusnaturalismo versus positivismo, onde aos princípios é reconhecido seu status de norma jurídica, e, portanto, autoaplicáveis (e não meras declarações de direitos).

Marlmestein, ao se referir sobre o que designa de "triunfo do Constitucionalismo", com a renovação dos quadros e do pensamento do Supremo Tribunal Federal, observa, analisando 
a produção da Corte, que "[...] hoje, está pacificado na jurisprudência do STF o entendimento de que, por força da máxima efetividade da constituição, é possível extrair dos princípios constitucionais comandos diretos ao legislador (2013, p. 29, grifo nosso)".

Para conhecer os princípios do Direito Ambiental consagrados em nossa Carta Política, deve-se começar (embora não se esgote aí) pelo Art. 225, abaixo transcrito:

Art. 225 - Todos têm direito ao meio ambiente ecologicamente equilibrado, bem de uso comum do povo e essencial à sadia qualidade de vida, impondo-se ao Poder Público e à coletividade o dever de defendê-lo e preservá-lo para as presentes e futuras gerações (BRASIL, 1988).

Não é objetivo deste paper fazer uma apresentação exaustiva dos princípios do Direito Ambiental, mas daqueles que incidem sobre a análise de constitucionalidade das normas que prescrevem incentivos fiscais para os agrotóxicos. É nesse recorte e nessa perspectiva que se fará essa análise.

Feita essa advertência, inicie-se esta análise dos princípios contidos nesta disposição normativa pelo Direito Fundamental ao Meio Ambiente Ecologicamente Equilibrado. Trata-se de um direito fundamental de terceira geração, na visão de Bonavides (2015), que contempla um processo cumulativo e qualitativo de conquistas, ou de terceira dimensão - na concepção de Sarlet (2014), que afirma, também, a unidade e indivisibilidade de todas as gerações/dimensões dos direitos fundamentais, decorrente do princípio da dignidade da pessoa humana, reconhecido no art. $1^{\circ}$, inciso III, da Constituição Federal.

É o próprio ditame do art. 225 que relaciona, como condição essencial à sadia qualidade de vida, à qualidade do meio ambiente, à sua higidez e ao seu equilíbrio. Não há, portanto, como se pensar uma vida digna em um ambiente - seja em sua dimensão natural, artificial ou cultural - que não seja equilibrado, saudável, sustentável. Por mais que haja diferenciados elencos de princípios na doutrina, existe quase um consenso de que o Princípio do Direito Fundamental ao Meio Ambiente Ecologicamente Equilibrado se configuraria como uma espécie de princípio dos princípios.

Machado é muito feliz quando articula o princípio do Direito Fundamental ao Meio Ambiente Ecologicamente Equilibrado com o princípio do direito à sadia qualidade de vida. Em suas palavras,

A saúde dos seres humanos não existe somente numa contraposição a não ter doenças diagnosticadas no presente. Leva-se em conta o estado dos elementos da Natureza - águas, solo, ar, flora, fauna e paisagem - para se aquilatar se esses 
Os benefícios fiscais para os agrotóxicos: um debate acerca de sua (in) constitucionalidade a partir do Estado de Direito Ambiental e da ordem pública ambiental

elementos estão em estado de sanidade e de seu uso advenham saúde ou doenças ou incômodos para os seres humanos (2014, p. 66).

Essa definição está em conformidade com o conceito de saúde da Organização Mundial de Saúde: "[...] um estado de completo bem-estar físico, mental e social e não somente ausência de afecções e enfermidades" (MEDICINA TROPICAL, 2015). É essa concepção que está presente no art. 196, inciso VIII, a consagrar a saúde como um dos direitos sociais fundamentais, sobretudo ao prescrever, em seu art. 200, que compete ao Sistema Único de Saúde (SUS)[...] colaborar na proteção do meio ambiente, nele incluído o do trabalho .

Outra grande inovação trazida pelo Direito Ambiental é a de que ao direito fundamental ambiental corresponde, também, um dever fundamental, superando tanto a visão liberal dos direitos individuais - em que se requer uma abstenção do Estado para sua fruição —, como a concepção dos direitos sociais, cuja formulação clássica é "direitos de todos, dever do Estado". Aqui, o direito fundamental é de todos; assim, também é de todos (do poder público e da coletividade, na dicção constitucional) o dever de defendê-lo e preservá-lo para as presentes e futuras gerações.

Está-se frente a uma das três fraturas paradigmáticas constatadas por Benjamin: "a diluição das posições formais rígidas entre credores e devedores (a todos se atribuem, simultaneamente, o direito ao meio ambiente ecologicamente equilibrado e o dever de protegê-lo)" (2008, p. 59).

Quando se refere ao dever fundamental do Estado, o art. 225 também emana outro princípio correlato, que encontra terminologias diferenciadas na doutrina, como "Princípio da Obrigatoriedade da Intervenção do Poder Público”, em Machado (2014, p. 134), ou, em uma visão mais ampliada e abrangente, o "Princípio da Natureza Pública da Proteção Ambiental", em Milaré (2013, p. 262). A materialização desse princípio, em sede constitucional, já vai ser encontrada nas incumbências previstas no parágrafo $1^{\circ}$ do art. 225.

Além do art. 225, esse princípio - dever fundamental do Estado ou obrigatoriedade de intervenção do poder público - vai ser encontrado ainda no art. 23, que trata da competência material comum aos entes da federação, que, em seus incisos VI e VII, estabelece, em matéria ambiental: [...] VI - proteger o meio ambiente e combater a poluição em qualquer de suas formas; VII - preservar as florestas, a fauna e a flora.

O enunciado de que o dever de proteção ao meio ambiente deve se voltar não só para as gerações presentes, mas também futuras, encerra, a um só tempo, dois princípios. O primeiro é voltado para a "família humana", conforme Milaré (2014, p. 261), que é o 
denominado de Solidariedade (ou Equidade) Intergeracional, que, a partir da constatação da finitude dos recursos naturais, compreende que as gerações futuras também têm o direito ao meio ambiente ecologicamente equilibrado.

Essa visão decorre do entendimento do que significaria o conceito - que também é um princípio (o segundo, portanto, do enunciado acima) de Direito Ambiental —, de "Desenvolvimento Sustentável", oriundo do documento intitulado Nosso Futuro Comum, de 1987, também conhecido como Relatório Brundtland, nome da primeira-ministra norueguesa que coordenou o trabalho a cargo da Comissão Mundial sobre Meio Ambiente e Desenvolvimento. É dali que vem a expressão (e objetivo do chamado desenvolvimento sustentável): “[...] atender às necessidades das atuais gerações sem comprometer as necessidades das futuras gerações". Objetivo no mínimo questionável, advirta-se, em uma organização societária como a capitalista, que se funda no crescimento ilimitado da economia, na transformação dos bens naturais em mercadorias e na busca desenfreada pelo lucro.

Ainda com relação aos princípios que interessam no debate acerca dos agrotóxicos, não poderia deixar de se falar no que Leite (2011, p. 32) denomina de princípio da precaução e da atuação preventiva, que se funda no princípio 15 da Declaração do Rio sobre Meio Ambiente e Desenvolvimento, da qual o Brasil é signatário, a saber:

Com o fim de proteger o meio ambiente, o princípio da precaução deverá ser amplamente observado pelos Estados, de acordo com suas capacidades. Quando houver ameaça de danos graves ou irreversíveis, a ausência de certeza científica absoluta não será utilizada como razão para o adiamento de medidas economicamente viáveis para prevenir a degradação ambiental. ${ }^{5}$

De forma bastante didática, Leite preleciona, ao unir o princípio da precaução com a atuação preventiva, que esta, tal como a precaução, "buscam remédios antecipatórios contra o dano ambiental, ou seja, criar condições para que não ocorram situações de degradação ambiental" (2011, p. 52).

Por último, mas não menos importante nesse esforço interpretativo, impende falar sobre o conceito de ordem pública ambiental desenvolvido por Benjamin (2008), em seu texto magistral aqui já citado. Esse importante conceito, que se materializa no art 225 e em vários outros dispositivos constitucionais, dá conta de que não se está "[...] diante de uma simples releitura da ordem privada [...] mas de admissão de uma ordem privada que se submete a uma ordem pública superior, sob o império de mandamentos e limites preambular e

\footnotetext{
${ }^{5}$ Declaração do Rio sobre Meio Ambiente e Desenvolvimento. Disponível em: <http://www.mma.go v.br/port/sdi/ea/documentos/convs/decl_rio92.pdf>. Acesso em 29 mar. 2015.
} 
Os benefícios fiscais para os agrotóxicos: um debate acerca de sua (in) constitucionalidade a partir do Estado de Direito Ambiental e da ordem pública ambiental

constitucionalmente fixados" (BENJAMIN, 2008, p. 123).

Dessa avançada concepção - inserida que está numa interpretação contemporânea que reconhece a força normativa da Constituição, a sua carga valorativa expressa nos princípios que sustentam o Estado de Direito Ambiental - decorre a compreensão de que o Direito Fundamental ao Meio Ambiente Ecologicamente Equilibrado é inapropriável, inalienável e imprescritível; portanto, não há de se reconhecer (aliás, se abomina, na forte expressão do autor) o direito adquirido de poluir, “[...] pois, não há direito contra o Direito, muito menos contra a Constituição" ((BENJAMIN, 2008, p. 218).

Conhecendo e interpretando as normas constitucionais aplicáveis à questão que se pretende discutir, passar-se-á à apresentação das normas que beneficiam, com incentivos fiscais, a produção, a importação e a comercialização dos agrotóxicos em nosso país.

\title{
3 A NORMA: OS INCENTIVOS FISCAIS PARA OS AGROTÓXICOS
}

\author{
"Mostrai-me a moeda do tributo. E eles lhe \\ apresentaram um dinheiro. E ele diz-lhes: De quem é \\ esta efígie e esta inscrição? \\ Dizem-lhe eles: De César. Então ele lhes disse: Dai pois \\ a César o que é de César, e a Deus o que é de Deus." \\ (Mateus, 22, 19-32).
}

No Brasil, a política de incentivos à utilização de agroquímicos se inicia, ainda no ano de 1975, com o Plano Nacional de Desenvolvimento Agrícola, que, conforme Rosa, Pessoa e Rigotto (2011, p. 218) anotam, “[...] incentivava e exigia o uso de agrotóxicos, oferecendo grandes investimentos para financiar esses 'insumos' e também ampliar a indústria de síntese e formulação no país, que passou de 14 fábricas em 1974 para 73 em 1985”.

Mas é por meio da extrafiscalidade - quando as normas tributárias têm sua finalidade instituída pelo legislador para além da simples arrecadação, utilizando-a como meio de influenciar a conduta humana - que se adotam as atuais políticas públicas de incentivos aos venenos agrícolas.

A extrafiscalidade pode se apresentar na forma positiva, como no caso da aplicada aos cigarros, em que o aumento do tributo ocasiona o aumento do valor do produto pela internalização de seu custo. O objetivo não é punir a prática nem indenizar os cofres públicos, visto que estas não são funções da tributação, mas sim desestimular o consumo (pelos impactos que causam à saúde e à vida humana e pelos gastos que acarretam ao sistema público de saúde), por meio do aumento dos preços, e, assim, cumprir a sua função 
arrecadatória.

A extrafiscalidade também pode se apresentar em sua forma negativa (incentivo, isenção tributária, subsídio), havendo por parte de alguns tributaristas uma preocupação com a diminuição da arrecadação mediante a aplicação destas normas indutoras (CAVALCANTE, 2014). No entanto, o que deve ser observado é que, com a adoção de práticas ambientalmente saudáveis, haverá uma economia para os cofres públicos. O incentivo a práticas protetivas evita a poluição e degradação ambiental, que provocam danos para a saudável qualidade de vida de toda uma sociedade, gerando custos para o Estado. A lógica é que se deixa de arrecadar em certo momento para diminuir os gastos caso houvesse a prática de atividades danosas.

Tal não é o caso das normas que concedem benefícios tributários à produção e à comercialização dos agrotóxicos, abaixo relacionados:

(i) No Convênio Confaz ${ }^{6}$ 100/97, ratificado pelo ato da Comissão Técnica Permanente (Cotepe) $\mathrm{N}^{\circ} 17 / 97$ houve a redução da base de cálculo dos produtos agrotóxicos em $60 \%$ :

Cláusula primeira - Fica reduzida em $60 \%$ (sessenta por cento) a base de cálculo do ICMS nas saídas interestaduais dos seguintes produtos: I - inseticidas, fungicidas, formicidas, herbicidas, parasiticidas, germicidas, acaricidas, nematicidas, raticidas, desfolhantes, dessecantes, espalhantes, adesivos, estimuladores e inibidores de crescimento (reguladores), vacinas, soros e medicamentos, produzidos para uso na agricultura e na pecuária, inclusive inoculantes, vedada a sua aplicação quando dada ao produto destinação diversa.

(ii) O Decreto Federal 5.630, de 22 de dezembro de 2005, que dispõe sobre a redução a zero das alíquotas da Contribuição para o PIS/PASEP e da Cofins incidentes na importação e na comercialização no mercado interno de adubos, fertilizantes, defensivos agropecuários e outros produtos;

(iii) O Decreto Federal 7.660, de 23 de dezembro de 2011, que isenta os agrotóxicos da cobrança de Imposto sobre Produtos Industrializados, o IPI.

Acresça-se que alguns estados ainda concedem uma redução ainda maior, como é o caso do Ceará: por força do Decreto Estadual 24.569, de 31 de julho de 1997, a redução da base de cálculo é $100 \%$, ou seja, isenção total do ICMS.

Ou seja, aqui, em sede de agrotóxicos, há uma espécie de "extrafiscalidade às avessas",

\footnotetext{
${ }^{6}$ O Conselho Nacional de Política Fazendária (Confaz) reúne os secretários de fazenda dos estados-membro, segundo seu regimento interno, teve sua criação destinada a elaborar e harmonizar procedimentos e normas inerentes ao exercício da competência tributária dos estados e do Distrito Federal. Nos termos do Decreto $\mathrm{n}^{\circ}$ 7.050, de 23 de dezembro de 2009, o Confaz é órgão colegiado que integra a estrutura do Ministério da Fazenda.
} 
Os benefícios fiscais para os agrotóxicos: um debate acerca de sua (in) constitucionalidade a partir do Estado de Direito Ambiental e da ordem pública ambiental

do ponto de vista ético e socioambiental, onde insumos responsáveis por danos graves ao meio ambiente e à saúde e à vida humana - a ponto de causarem milhares de óbitos em todo o país - têm incentivos semelhantes ou menores até que os produtos agrícolas da cesta básica ${ }^{7}$, quando o justo e racional é que aqueles, os agrotóxicos, sejam tratados - e sobretaxados como cigarros e bebidas, a fim de inibir, e não incentivar, o seu uso.

É de se compartilhar o mesmo "estranhamento" expresso por Pacobahyba: “[...] a utilização de uma sanção premial, tal como preceituada por Bobbio, a fim de estimular um comércio nitidamente danoso ao meio ambiente" (2011, p. 272).

A questão, evidentemente, não se cinge ao debate no âmbito tributário, mas, principalmente, volta-se à hermenêutica jurídica, constitucional e ambiental, objeto deste paper e que será enfrentado nas conclusões.

\title{
CONCLUSÕES
}

\author{
"A abelha por Deus foi amestrada \\ Sem haver um processo bioquímico \\ Até hoje não houve nenhum químico \\ Pra fazer a ciência dizer nada...” (Zé Ramalho)
}

O Brasil é o maior consumidor mundial de agrotóxicos, e isso se deve, certamente, às políticas públicas de incentivo aos venenos agrícolas, desde o Plano Nacional de Desenvolvimento Agrícola, na década de 1970, até a atual política que concede benefícios fiscais ao uso, comercialização, produção e importação daqueles insumos.

O uso dos agrotóxicos em nosso país é responsável pelo envenenamento do meio ambiente natural - água, ar, solo, plantas e animais - e das populações humanas, desde os que trabalham em fábricas e fazendas, até o consumidor final, dado o seu elevado grau de contaminação. É altamente questionável o uso de seguro de agrotóxicos.

A Constituição de 1988 instituiu em nosso país uma nova ordem pública, a ordem pública ambiental, decorrente da fórmula política que fundamenta a Carta, o Estado de Direito Ambiental, calcado em princípios que asseguram o direito e o dever fundamental do meio ambiente, o direito à saúde, a solidariedade intergeracional e a precaução e atuação preventiva.

As normas que concedem benefícios tributários ao uso, comercialização, produção e

\footnotetext{
${ }^{7}$ No Estado do Ceará os produtos constantes da cesta básica percebem uma redução de apenas 58,82\% na alíquota de ICMS (lei $\mathrm{n}^{\circ} 12.670$, de 30 de dezembro de 1996).
} 
importação de agrotóxicos, fundadas em uma espécie de "extrafiscalidade às avessas" porque injusta, aética e insustentável -, contrariam os princípios constitucionais, a ordem pública ambiental e o Estado de Direito Ambiental, que consubstanciam valores eleitos pela Carta Política. Pode-se, então, considerar inconstitucionais as normas acima referidas.

O fim das isenções tributárias aos agrotóxicos é uma das cinco bandeiras (as outras são: o fim da pulverização aérea; o banimento imediato dos agrotóxicos que já são proibidos em outros países; a proteção dos recursos hídricos e a criação de áreas livres de agrotóxicos e transgênicos) da Campanha Permanente Contra os Agrotóxicos e Pela Vida, que reúne mais de 100 entidades nacionais da sociedade civil e que tem o objetivo de sensibilizar o conjunto da população para os riscos que esses venenos representam para a saúde e o meio ambiente, bem como debater um novo modelo de produção alimentícia, baseado nos princípios da Agroecologia ${ }^{8}$.

Nesse processo de sensibilização e mobilização, duas ferramentas têm se mostrado de importância fundamental: o Dossiê da Associação Brasileira de Saúde Comunitária (ABRASCO) sobre os impactos dos agrotóxicos na saúde ${ }^{9}$ e os documentários $\mathrm{O}$ veneno está na mesa 1 e 2 , ambos de autoria do cineasta Silvio Tendler ${ }^{10}$, que tratam tanto das denúncias dos males dos agrotóxicos como das alternativas agroecológicas.

É fato que a decisão sobre a constitucionalidade de lei ou ato normativo, no direito brasileiro, é competência de nossa Corte Constitucional, o Supremo Tribunal Federal, por conta do que dispõe o art 102, I, "a" de nossa Carta Política. Contudo, nesse percurso - que envolve lutas sociais, pesquisas acadêmicas e embates judiciais -, a decisão por parte da Justiça Trabalhista do Ceará de responsabilização de uma empresa pela morte de um trabalhador que manejava agrotóxicos (já acima referida), assim como ações como a do Ministério Público Federal de São Paulo, que propõe o banimento de venenos cancerígenos (BRASIL, 2015) ${ }^{11}$ são iniciativas da maior importância no sentido de fortalecer a compreensão de que, em defesa da saúde e o do meio ambiente, devemos lutar pela inconstitucionalidade de qualquer benefício fiscal à produção, ao consumo, à importação e ao uso de agrotóxicos em nosso país.

\footnotetext{
${ }^{8}$ Disponível em: 〈http://www.contraosagrotoxicos.org/>.

${ }^{9}$ Disponível em: <http://abrasco.org.br/dossieagrotoxicos/>

${ }^{10}$ Disponível em: 〈https://youtu.be/ YyUN-g-iR0 e https://www.youtube.com/watch?v=fyvoKljtvG4>.

${ }^{11}$ Disponível em: <http://noticias.pgr.mpf.mp.br/noticias/noticias-do-site/copy of meio-ambiente-e-patrimoniocultural/mpf-sp-quer-que-agrotoxicos-contendo-ingrediente-cancerigeno-sejam-proibidos-no-pais $>$. Acessos em 21.12.2016
} 
Os benefícios fiscais para os agrotóxicos: um debate acerca de sua (in) constitucionalidade a partir do Estado de Direito Ambiental e da ordem pública ambiental

\section{REFERÊNCIAS}

AUGUSTO, Lia Giraldo da Silva et al.. O contexto de vulnerabilidade e de nocividade do uso dos agrotóxicos para o meio ambiente e a importância para a saúde humana. In: RIGOTTO, Rachel (org.). Agrotóxicos, trabalho e saúde: vulnerabilidade e resistência no contexto da modernização agrícola no Baixo Jaguaribe/CE. Fortaleza: Edições UFC, 2011.

BELCHIOR, Germana Parente Neiva. Hermenêutica Jurídica Ambiental. São Paulo: Saraiva, 2011.

BENJAMIN, Antonio Herman. Constitucionalização do ambiente e ecologização da Constituição Brasileira. In: CANOTILHO, José Joaquim Gomes; LEITE, José Rubens Morato. Direito Constitucional Ambiental Brasileiro. 2. ed. Ver. São Paulo: Saraiva, 2008. BONAVIDES, Paulo. Curso de Direito Constitucional. 30 ed. São Paulo: Malheiros, 2015. CANOTILHO, José Joaquim Gomes. Direito Constitucional Ambiental Português e da União Europeia. In: CANOTILHO, José Joaquim Gomes; LEITE, José Rubens Morato. Direito Constitucional Ambiental Brasileiro. 2. ed. Ver. São Paulo: Saraiva, 2008.

CARNEIRO, Fernando Ferreira et al. (Org.). Dossiê ABRASCO: um alerta sobre os impactos dos agrotóxicos na saúde. Rio de Janeiro: EPSJV; São Paulo: Expressão Popular, 2015.

CAVALCANTE, Denise Lucena. Instrumentos fiscais na efetivação da política nacional de resíduos sólidos: do poluidor-pagador ao protetor-recebedor. In CAVALCANTE, Denise Lucena (org.). Tributação ambiental: reflexos na Política Nacional de Resíduos Sólidos. Curitiba: CRV, 2014.

CODONHO, Maria Leonor Paes Cavalcanti Ferreira. Desafios para a concretização da agricultura sustentável no Brasil: uma contribuição do direito para a regulação do uso dos agrotóxicos. São Paulo: Instituto O Direito por um Planeta Verde, 2014.

DIÁRIO DO NORDESTE. TRT mantém decisão que condena multinacional. Disponível em: <http://diariodonordeste.verdesmares.com.br/cadernos/cidade/trt-mantem-decisao-quecondena-multinacional-1.1150525>. Acesso em: 29 mar. 2015.

FOSTER, John Bellamy. A Ecologia de Marx: materialismo e natureza. Tradução de Maria Teresa Machado. Rio de Janeiro: Civilização Brasileira, 2005.

PAINEL INTERGOVERNAMENTAL SOBRE MUDANÇAS CLIMÁTICAS. Fifth Assessment Report (AR5). Disponível em: <http://www.ipcc.ch/report/ar5/in dex.shtml> . Acesso em: 28 mar. 2015. 
João Alfredo Telles Melo e Geovana de Oliveira Patrício Marques

JUSBRASIL. Dissertação de mestrado derruba mito do uso seguro de agrotóxicos.

Disponível em: <http://carollinasalle.jusbrasil.com.br/noticias/146505923/dissertacao-demestrado-derruba-mito-do-uso-seguro-de-agrotoxicos?utm_campaign=newsletterdaily_20141021_215\&utm_medium=email\&utm_source=newsletter>. Acesso em: 29 mar. 2015.

LEITE, José Rubens Morato. Dano Ambiental: do individual ao coletivo extrapatrimonial: teoria e prática. 4. ed. atual. e ampl. São Paulo: Editora Revista dos Tribunais, 2011.

LONDRES, Flávia. Agrotóxicos no Brasil: um guia para a ação em defesa da vida. Rio de Janeiro: AS-PTA - Assessoria e Serviços a Projetos em Agricultura Alternativa, 2011.

MACHADO, Paulo Affonso Leme. Direito Ambiental Brasileiro. 22.ed., ver, ampl., e atual., São Paulo: Malheiros, 2014.

MARLMESTEIN, George Lima. 25 anos da Constituição de 1988: presente, passado e futuro. In: CARVALHO, Paulo Rogério Marques de Carvalho; ROCHA, Maria Vital da Rocha, (org.). 25 anos da Constituição de 1988: os direitos fundamentais em perspectiva. Fortaleza: Expressão Gráfica, 2013.

MEDICINA TROPICAL. Conceito de Saúde. Disponível em < http://www.alternativamedi cina.com/medicina-tropical/conceito-saude>. Acesso em: 29 mar. 2015.

MILARÉ, Édis. Direito do Ambiente. 9. Ed. Ver., atual. E ampl. São Paulo: Revista dos Tribunais, 2014.

MORIN, Edgar; KERN, Anne-Brigitte. Terra-Pátria. Tradução de Paulo Azevedo Neves da Silva. 5. Ed. Porto Alegre: Sulina, 2005.

NODARI, Rubens Onofre. Risco à saúde dos seres vivos adindo dos agrotóxicos: ênfase nos herbicidas. In ARAGÃO, Alexandra et al (org.). Agrotóxicos. A nossa saúde e o meio ambiente em questão: aspectos técnicos, jurídicos e éticos. Florianópolis: FUNJAB, 2012.

ORGANIZAÇÃO MUNDIAL DE SAÚDE. 7 milhões de mortes em 2012 foram associadas à poluição. Disponível em: <http://agenciabrasil.ebc.com.br/internacional/noticia/201403/oms-7-milhoes-de-mortes-em-2012-foram-sassociadas-poluicao>. Acesso em: 28 mar. 2015.

PACOBAHYBA, Fernanda Mara de Oliveira Macedo Carneiro. A concessão de benefícios fiscais pelos Estados na contramão da democracia brasileira. Meritum, Belo Horizonte, v. 6, n. 1, jan./jun. 2011.

ROSA, Islene Ferreira; PESSOA, Vanira Matos; RIGOTTO, Raquel Maria. Introdução: agrotóxicos, saúde humana e os caminhos do estudo epidemiológico. In: RIGOTTO, Rachel 
Os benefícios fiscais para os agrotóxicos: um debate acerca de sua (in) constitucionalidade a partir do Estado de Direito Ambiental e da ordem pública ambiental

(org.). Agrotóxicos, trabalho e saúde: vulnerabilidade e resistência no contexto da modernização agrícola no Baixo Jaguaribe/CE. Fortaleza: Edições UFC, 2011.

SARLET, Ingo Wolfgang. A eficácia dos Direitos Fundamentais. 11ed. Porto Alegre: Livraria do Advogado Editora, 2014.

SARLET, Ingo Wolfgang; FENSTERSEIFER, Tiago. Estado socioambiental e mínimo existencial (ecológico?): algumas aproximações. Estado socioambiental e direitos fundamentais. Porto Alegre: Livraria do Advogado Editora, 2010.

SILVA, Claudio. Trabalho, agrotóxicos e morte no campo: uma longa espera. Disponível em: <http://www.ecodebate.com.br/2014/03/28/trabalho-agrotoxicos-e-morte-no-campouma-longa-espera-por-justica-por-claudio-silva/>. Acesso em: 29 mar. 2015.

TUMA, Rogério. Antropoceno: a era da destruição. Disponível em: <https://br.groups. yahoo.com/neo/groups/MCTAD_UFV/conversations/topics/1454>. Acesso em 28 mar. 2015. UOL. Disponível em: <http://noticias.uol.com.br/ultnot/afp/2007/01/31/ult1806u5420.jhtm>. Acesso em 28 mar. 2015.

VALOR ECONÔMICO. Vendas de defensivos batem novo recorde. Valor Agronegócios, 17 abr. 2013. Disponível em: <http://www.valor.com.br/empresas/3089652/vendas-dedefensivos-batem-novo-recorde>. Acesso em: 01 fev. 2016. 